\title{
Augmented Reality App for Teaching OOP
}

\author{
Sana Rizwan ${ }^{1}$, Arslan Aslam ${ }^{2}$, Sobia Usman ${ }^{3}$, Muhammad Moeez Ghauri ${ }^{4}$ \\ Department of Computer Science, COMSATS University Islamabad, Lahore Campus, Pakistan
}

\begin{abstract}
Now a days, there is demanding needs of developing interactive mediums of study. As our conventional methods of learning are not very effective. Programming has become one of the core subjects of every field of study due to their vast use. However, introducing computer programming to those students who's are not familiar with programming is a tough task. Use interactive learning through visual effects using AR (Augmented Reality) developed to provide a platform for new students to interact more in learning environment. As this learning environment becomes more effective it is easier for new comers to understand key concepts of programming more effective way.
\end{abstract}

Keywords-Augmented reality; object-oriented programming; unity; visualization; human computer interaction; Vuforia; rendering; compiler

\section{INTRODUCTION}

Application will allow the people to visualize the OOP concepts and check their interactions and effects to understand them easily with efficiency rather than just sitting and thinking about them by using and visually seeing them their rate of progress will increase.

Although there is lot of e-learning application available on online platforms but there is no special application for objectoriented programming. This project consists of a web application and an android application. Web portion is consisting of textual based tutorials for learning and android application is for visual learning.

\section{LITERATURE REVIEW}

The importance of learning through computer starts from 21 th century and their importance gradually increase with the passage of time. Programming is one of basic course required in any computer science related field. For most of the students, it is also one of the most challenging tasks that how to understand coding or how to write a computer program. For improving the novice experience with learning to program, visual environments and effects can be designed. At university level as well as the industry have placed increasing importance on the early experience of students to objectoriented programming (OOP).

There is a need to develop an interactive e-learning environment for students to overcome the challenge of learn programming. Incredible developments had been occurring in computer technology and its availability in that time duration. Computer technology used for learning in schools, universities, business market, industries and the many other professions in last ten years. So, the number of learning software's and applications has growth dramatically.
Traditional methods of study are more complex, boring and time taking. The field Human computer interaction directs us to how to make an interactive application? What are the requirements of user? What are the problems faced by users? What the user needed? There are some questions invoke at every developer while he/she build an application of software. HCI gives the better ways to develop an interactive application. Students' who learn in an e-learning environment would be independent of distance, time, computing platform as well as classroom size also.

The knowledge needed to write a computer program is an important part of literacy in modern society. While private coding classes are expensive and limited.

In programming some of the most difficult things to understand are concepts that we use to develop data structures and algorithms. Sometimes even for the more intelligent people they cannot understand some concepts due to the fact that each person has a different mind-set.

This application will allow such people to visualize such concepts and check their interactions and affects to understand them easily with efficiency rather than just sitting and thinking about them by using and visually seeing them their rate of progress will increase.

Although there is lots of e-learning application available on online platforms but there is no special application for object-oriented programming. This project consists of a web application and an android application. Web portion is consisting of textual based tutorials for learning and android application is for visual learning.

Originally this approach of learning started in the more developed countries of the world such as U.S.A and U.K in these countries to improve the education system e-learning was introduced now though with the advent of augmented and virtual reality, this system of e-learning is being taken a step further by making learning more interactive and hence more interesting by using such technologies. In such developed countries such application has started being widely used in young children [3], hence our aim is the same to increase education efficiency by using these technologies.

Moreover, The School Education Department of Punjab has been working closely with Punjab Information Technology Board (PITB) to develop and implement Elearning solutions for secondary and higher secondary students in which, PCTB textbooks for Grades 6 through 10 have been digitised and augmented with thousands of interactive multimedia components like Animations, Simulations, 3D models and videos. [2] 
More related works would be those that follow the four steps [4], to teach students through e-learning, due to the fact that much of the increase in understanding comes from use of what is known as "visual literacy." Visual literacy is defined as the ability to understand data and information presented in a pictorial format or graphic images [1], Visual literacy has been proven to enhance learning especially in subjects where they do not have much prior knowledge. [5].

In fact, studies show that using graphics in instructional modules promotes greater understanding in general. It is in fact proven that less is more beneficial if it can be better understood [8], Logic building process is also a tough task for students and many students confused about different approaches to solve some programming problem. These aspects would be challenging for teachers and students [6], and the learning of the application of what is being learnt while it is being learnt is important [7], Researcher shows the object-oriented concept. Some concepts students understand properly but some concept cannot understand. It finally points difficulties in some areas and result, planning to give an easy and effective way to teaches OOP [9], by participating in applied task, the comprehension of the subject becomes better [10].

It is known through research that the programming skills of first year students are not up to the required level as most of them have not been exposed to how to solve tasks and do programming [11] hence in the past there have been many application that have focused on teaching beginners how to code but in most of these applications the user only learns the syntax and does not have an editor to practise it side by side and while it is important to know how to build a solution [12] it is also better to at least once make the solution as well because it cements our understanding, there have also been many lone editors for the java language but they are complicated and not very good for beginners to work on, while in the system we are proposing we will try to combine both an explainer as well as an editor with visual representations to allow the user to quickly understand concepts and learn the language efficiently as in interactive setting the user unknowingly tries harder [13].

\section{INTERFACES}

Augmented Reality followed basic human interaction usability principles in user interface creation. Consistent interface and design present across all modules. By default, augmented reality opens in full screen mode in landscape orientation on some specific devices those who have sensors to show augmented objects. Interface is compatible with cross devices. Based on human computer interaction methods, we design interfaces very user friendly.

Following are prime interfaces components.

\section{A. Explainer}

Explainer is mean interface component of project. This module consists of basic concepts tutorials of object-oriented programming. Every tutorial consists of three sections such as topic name, topic explanation and try yourself code as shown in Fig. 1. We provided the code examples of every topic which is easy to understand and make changes in practice code also available through compiler. User with be able to discuss or ask any question about the topic in comment section. Because it's an interactive web application so tutorials are locked once someone take a tutorial about some topic the next task is to give a simple multiple-choice quiz. After successfully completed the quiz then the user moves towards next tutorial and so on.

\section{B. Compiler}

Compiler is basically for try yourself section that user pic example code of some specific topic and makes changes in it as shown in Fig. 2: Compiler able to work with multiple classes of object-oriented programming. As in case of any wrong code written by user Errors also shows with line number on console panel.

\section{Quiz}

Fig. 3 shows quiz section consists of multiple choice-based questions. Answers will be provided also for confirmation of selected choice. A progress bar will be saving the quiz data of users.

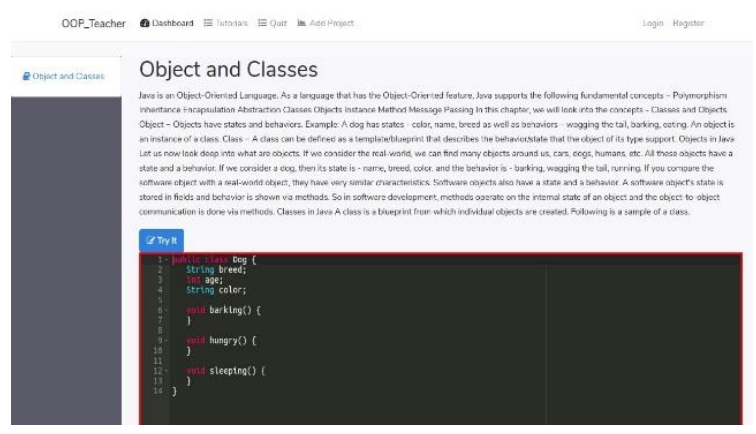

Fig. 1. Explainer

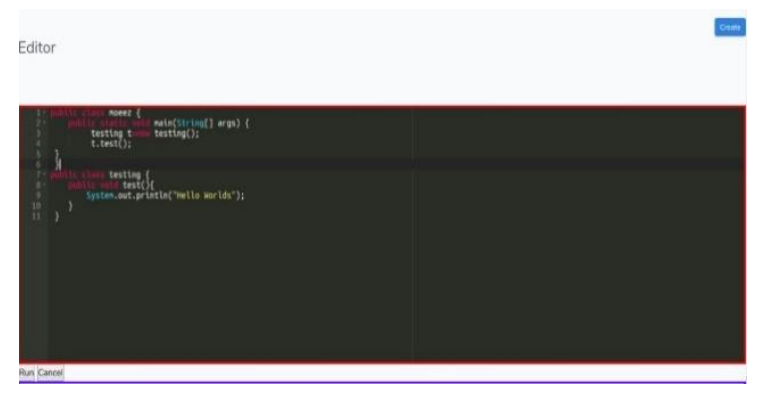

Fig. 2. Compiler.

Which access modifier explicitly says that a method or variable of an object can be accessed by code from outside of the class of that object?

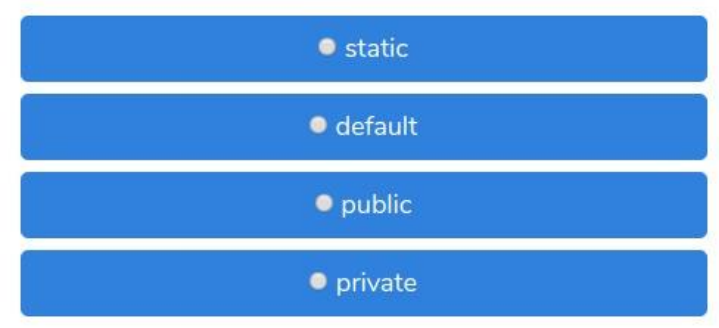

Fig. 3. Quiz. 


\section{Rendering Screen}

Majority part of user interface cover by Rendering screen. Rendering screen helps us to seen Augmented reality (AR) components. One important thing that AR not supports with all the mobile devices, but some specific mobile devices shows AR object through camera to see elements present in surrounding.

\section{METHODOLOGY}

Augmented Reality follows visual based interactive learning method to teach programming. The field of HumanComputer Interaction (HCI) or in other words show something by using visual effects is focused on enhancement the effectiveness as well as efficiency of human-computer interfaces through the development of both hardware and software designs to recognize human characteristics and behavior. Advancements in HCI technology can lead to enhanced Augmented reality (AR) experiences by providing more natural like environment and efficient methods for a user to interact with a real or virtual environment in an effective way.

\section{A. Software Architecture}

Fig. 4 shows software architecture. According to software architecture user interacts with web application or android application and moves towards explainer section for learning and editor section to explore learning concepts and tryout code examples with the help of compiler. All the learning data managed by an admin and only admin have authority to add, update or delete data in database. User might be suggesting some things in comments section as feedback.

\section{B. Compiler}

We make an API in java for makes an online compiler which code shows in Fig. 5 and integrate it to Laravel framework. We used library "Tools and Diagnostics" for multiclass compiler. This compiler saves all the classes into an array and separated with Java API basically is a JAR file which is run by using CMD.

\section{Augmented Reality (AR) apps with unity and Vuforia}

We can use AR to teach the concepts of OOP in more optimal manner. Augmented Reality can be used to teach OOP concepts. Inheritance can be taught using AR based mobile devices. Similarly, the concept of composition, aggregation, polymorphism etc. also taught by using AR app. We prepare the models of CAR which shows in Fig. 6, 7 and HUMAN which shows in Fig. 8. Firstly, we show that how to initialize an object in OOP then we move towards other major concepts of OOP. Make models of AR in unity 3D \& Vuforia.

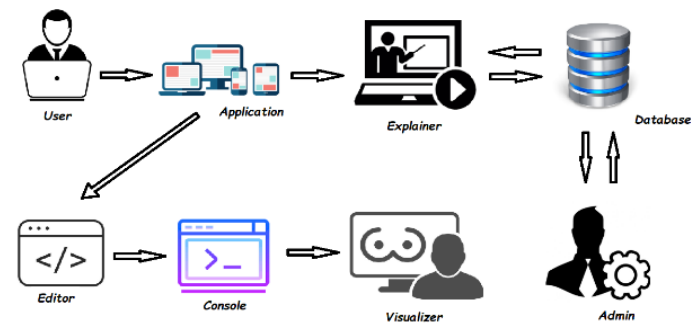

Fig. 4. Software Architecture.

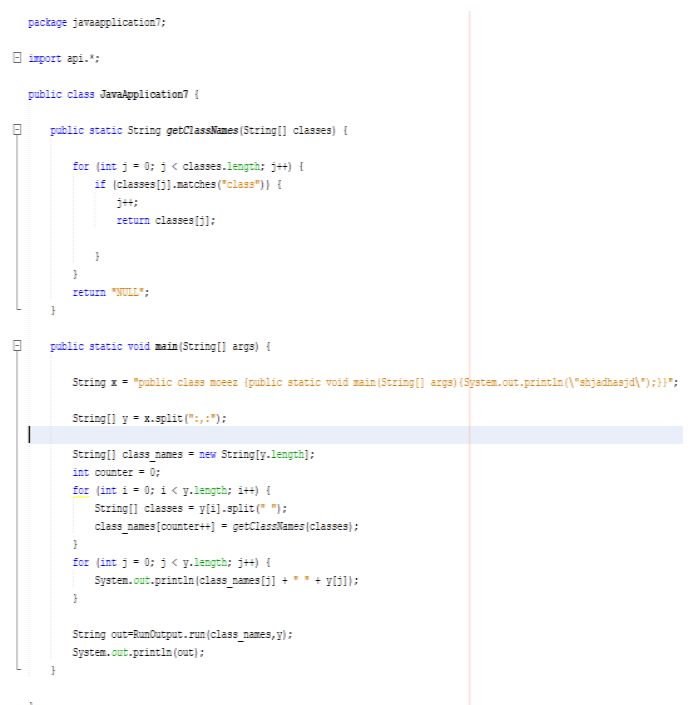

Fig. 5. Compiler.

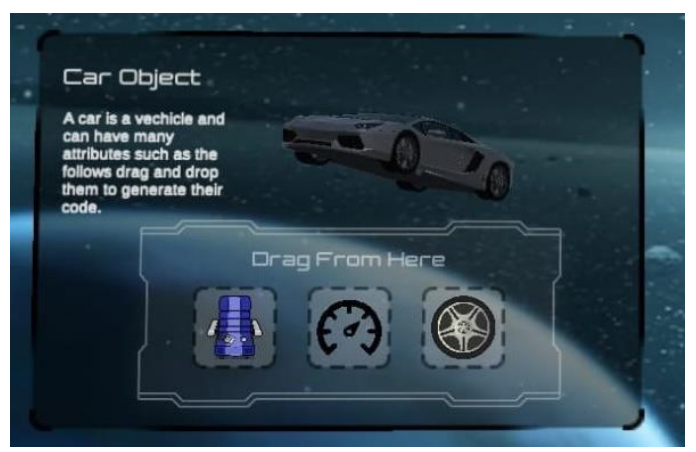

Fig. 6. Augmented Reality App (Car Model (1)).

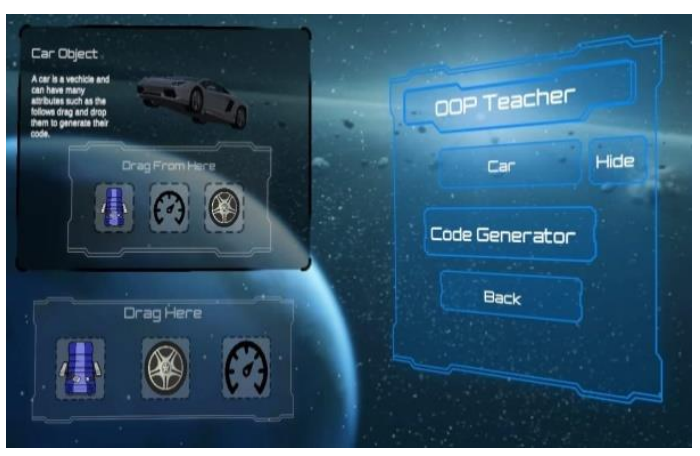

Fig. 7. Augmented Reality App (Car Model (2)).

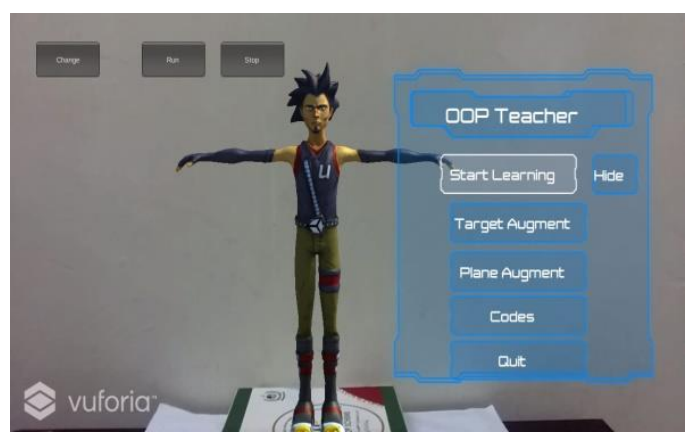

Fig. 8. Augmented Reality App (Human Model). 


\section{RESULTS AND DISCUSSION}

According to studies, it is observed that how augmented reality can be useful in teaching prospective such as for OOP concepts. It is more practical way to teach students in an artful environment. It is interesting and growing field. But lack of resources, awareness and devices that field not the part of studies even in modern institutes.

Augment reality gives us optimal solutions. By using methods and techniques of $\mathrm{AR}$ will make revolutionary changes in traditional learning process and enhance the modern learning techniques. The main purpose of this research is to find out the ways in which AR can be used in studies and we focus on OOP concepts and try out to develop a system which is more user friendly. We initially targeted small amount of population because everyone has not AR supported devices only few mobiles with specific sensors would be able to run an AR based application.

\section{CONCLUSION}

Augmented reality is a new concept but can use generate optimal results. In the education field, it can be used in a very effective manner as it can be used to teach some concepts in a more practical way to students. Use of AR will make revolutionary changes in traditional teacher entered teaching process in future.

\section{FUTURE WORK}

The project can be extended to theoretically all the programming languages as this is in essence a tool for elearning using visual techniques, in the future, this application can be enhanced to follow "one size fits all" concept. Web Programming as well as Database Programming can also be included as in databases, we also require large amounts of visualizations and have to ponder upon the many what ifs. Machine learning techniques can be used to provide exercises to users based on their progress. This application can be made in game type theme in which user can progress only by completing a previous task to a satisfactory level. This will allow for more immersion and not let the user get bored. This application can be further extended to the professional level. This can also be really helpful for the beginners. More over the system can with some time include its own compiler that can visually show objects which will form basis for a simulator for testing running of the application.

\section{REFERENCES}

[1] Suzanne Stokes. Visual Literacy in Teaching and Learning: A Literature Perspective. Electronic Journal for the Integration of Technology in Education, vol. 1, no. 1.

[2] https://elearn.punjab.gov.pk

[3] Tanvi Patel. Learning Object Oriented Programming Using Augmented Reality: A Case Study with Elementary School Students

[4] Hinterberger, H., 'E-Learnig: Make it as simple as possible, but not simpler'. Afr. Technol. Dev. Forum Journal, Vol. 4, Issue 2, July, 2007.

[5] Chanlin, L. (1997). The effects of verbal elaboration and visual elaboration on student learning.

[6] International Journal of Instructional Media, 24(4), 333-339. Retrieved December 26, 2001, from EBSCOhost database (Academic Search Elite).

[7] Heinich, R., Molenda, M., Russell, J. D., \& Smaldino, S. E. (1999). Instructional media and technologies for learning (6th ed.). Upper Saddle River, NJ: Prentice-Hall.

[8] Mayer, R. E., Bove, W., Bryman, A., Mars, R., \& Tapangco, L. (1996). When less is more: Meaningful learning from visual and verbal summaries of science textbook lessons. Journal of Educational Psychology, 88(1), 64-73.

[9] Kelleher, C. and Pausch, R. Lowering the barriers to programming: A taxonomy of programming environments and languages for novice programmers. ACM Computing Surveys 37, 2 (June 2005), 83-137.

[10] Tony J. A Participative Approach to Teaching Programming, ACM SIGCSE, Volume 30 Issue 3, Sept. 1998, Pages 125-129 1998.

[11] M. McCracken, V. Almstrum, D. Diaz, M. G. anD. ianne Hagan, Y. B. Kolikant, C. Laxer, L. Thomas, I. Utting, and T. Wilusz. A multinational, multi-institutional study of assessment of programming skills of first-year CS students. SIGCSE Bulletin, 33(4):125- 180, 2001.

[12] Elliot Soloway. Learning to Program = Learning to Construct Mechanisms and Explanation, 1986.

[13] Malone, T. (1980). What makes things fun to learn? Heuristics for designing instructional computer games. Proceedings of the 3rd ACM SIGSMALL Symposium and the 1st SIGPC Symposium (pp. 162-169). Palo Alto, US. 